\title{
Business Process Management Culture in Public Administration and Its Determinants
}

\author{
Ingo Kregel 1 - Bettina Distel 1 - André Coners
}

Received: 17 January 2020/Accepted: 1 June 2021/Published online: 26 August 2021

(C) The Author(s) 2021

\begin{abstract}
Public administration institutions increasingly use business process management (BPM) to innovate internal operations, increase process performance and improve their services. Research on private sector companies has shown that organizational culture may impact an organization's BPM and this culture is often referred to as BPM culture. However, similar research on public administration is yet missing. Thus, this article assesses BPM culture in Germany's municipal administration. 733 online survey responses were gathered and analyzed using MANOVA and follow-up discriminant analyses to identify possible determinants of public administration's BPM culture. The results indicate that the employees' professional experience and their responsibility influence the assessment of BPM culture, as does the size of a municipality. Based on these findings, the article proposes testable relationships and an agenda for further research on BPM culture in public administration.
\end{abstract}

Accepted after three revisions by Jan Mendling.

I. Kregel $(\square)$

Faculty of Business Studies, Dortmund University of Applied

Sciences and Arts, Emil-Figge-Str. 44, 44227 Dortmund,

Germany

e-mail: ingo.kregel@fh-dortmund.de

B. Distel

European Research Center for Information Systems, University of Münster, Leonardo-Campus 3, 48149 Münster, Germany

\section{A. Coners}

Department of Applied Business and Technology Management, South Westphalia University of Applied Sciences, Haldener Str. 182, 58095 Hagen, Germany
Keywords Business process management · Organizational culture - BPM culture - Explorative research - Public administration $\cdot$ Local government

\section{Introduction}

After decades of reform and modernization, one of the current challenges for public management is digital transformation. Most current jobs will likely be affected, changed, digitalized, automated or even become obsolete (Frey and Osborne 2017). Additionally, the various stakeholders of public administration expect new ways to interact with the administration and more efficient encounters (Dunleavy et al. 2006; Lindgren et al. 2019). The digital transformation therefore requires and entails fundamental changes to business processes (Denner et al. 2018; Legner et al. 2017; Mendling et al. 2020). For a successful transformation, technical and organizational changes must go hand in hand (Indihar-Štemberger and Jaklič 2007). Business process management (BPM) presents a comprehensive management approach to handle an organization's processes and has proven to have a positive influence on organizational performance (Hammer 2015; Rosemann and vom Brocke 2015). As in most fields of management research, the context of BPM is of great importance for its success (Johns 2017; Zelt et al. 2018). Previous work acknowledges that the industry is one of the typical contextual factors of BPM that shapes the configuration of approaches, methods and models (vom Brocke et al. 2016; vom Brocke et al. 2021). As BPM gained popularity in the public sector, scholars have investigated the specificities of public administration that may impact BPM tools and methods (e.g. Indihar-Štemberger and Jaklič 2007), the public sector's BPM capabilities (e.g. 
Niehaves et al. 2013) and more specific topics, such as business process verification in the public sector (e.g. Corradini et al. 2015). However, the influence of organizational culture on BPM initiatives has only been subject to sector-independent studies and the specifics of public administration have not been analyzed in depth.

The importance and influence of culture on information systems and on BPM is recognized by the research community (Heinzl and Leidner 2012). While current research often focuses on BPM methods such as process modelling, lean management and Six Sigma, less attention has been paid to the impact of an organization's culture on its BPM success (vom Brocke and Sinnl 2011). So far, the few scholars who have systematically studied the relationship between BPM and organizational culture suggest that culture has a significant influence on BPM (Weber and Dacin 2011). To address this issue, Schmiedel et al. (2014) developed a framework of BPM culture and a standardized questionnaire to measure process-oriented culture in organizations, the BPM Culture Assessment. This instrument was tested with respondents from various industries such as information technology, banking \& financial services and engineering \& construction (Schmiedel et al. 2014, 2020). However, only a very small number of public sector respondents was included and the results were not analyzed with regard to the different sectors and contexts. Thus, we address the question: "How and by which determinants is BPM culture shaped in public administration?" To explore this application domain in more detail, this RQ is subdivided into three important aspects, which is why we address the following specific research objectives (RO):

RO1: Test the applicability of the BPM Culture Assessment in the public sector.

$\mathrm{RO} 2$ : Identify determinants for the eight dimensions of BPM culture in public administration and propose testable relationships between BPM culture and external determinants.

RO3: Propose a research agenda for BPM culture in the public sector.

Thus, this article seeks to test both the applicability of the instrument in a public sector context regarding more formal aspects, such as wording and use of technical terms, and the content-related adequacy of the instrument. Furthermore, the study assesses the eight dimensions of BPM culture in public administration as proposed in the framework by Schmiedel et al. (2014) and is focused on understanding how and by which factors this culture could be shaped. Our research therefore is explorative in that we adapt and transfer a validated, yet not extensively used instrument to a new context. As explorative research can be followed by explanatory research (Flynn et al. 1990), we propose testable relationships and a research agenda as results of our study.

By addressing the above outlined research question and objectives, this study offers three central contributions to current debates in both BPM- and public sector-related research. First, we apply the BPM Culture Assessment to the public sector context. In doing so, we advance knowledge on BPM culture by offering an adjusted instrument, the BPM Culture Assessment for Public Administration. The refined instrument can be used by both researchers and practitioners to benchmark and investigate BPM culture in public administration. Second, the empirical analysis reveals insights that are specific for the public sector context addressed in this study. Inter alia, the results emphasize that many private sector logics cannot be applied one-on-one to public administration. Research on BPM in general and BPM culture in particular needs to consider the context in which organizations operate and treat public administration as an application domain of its own. Third, we derive an agenda for future research on BPM culture in public administration that can serve as basis for advancing knowledge in this still nascent research field.

We start this article by summarizing existing research on organizational and BPM culture. In Sect. 2, we also take a closer look at the research into organizational and BPM culture in the public sector. Section 3 introduces the instrument and summarizes the research design and method (online survey). Results of the survey are presented in Sect. 4 and subsequently discussed in Sect. 5. We conclude this article with a short summary.

\section{Research Background}

\subsection{Business Process Management Culture}

According to Schein (1996), culture describes "shared norms, values and assumptions" which can be observed in a group or organization. Measuring organizational culture has been subject to research for decades (Hofstede et al. 1990). The manifold values of an organization can be of different interest levels depending on the research focus. While scholars have investigated the organizational culture in public agencies in general (Zhang and Feeney 2020), less attention has been paid to the organizational culture in relation to BPM. Thus, this study specifically targets BPM culture which describes an organization's ability to support BPM (Armistead et al. 1999; Zairi 1997).

BPM can be defined as a "body of methods, techniques, and tools to identify, discover, analyze, redesign, execute, and monitor business processes in order to optimize their performance" (Dumas et al. 2018). In public 
administration, many process change initiatives fail or do not achieve the planned results (Radnor and Osborne 2013). Organizational culture is one of the commonly identified factors that contribute to those setbacks (Baird et al. 2011; Radnor and O'Mahoney 2013). Research on the influence of organizational culture on the success of BPM initiatives in general has intensified during the past 20 years (Indihar Štemberger et al. 2018; Leidner and Kayworth 2006; $\mathrm{Zu}$ et al. 2010). Several studies confirm positive effects of process-orientation on financial as well as non-financial performance in private sector companies (McCormack and Johnson 2001; Škrinjar et al. 2008). However, research on the characteristics of BPM culture in the public sector remains scarce.

Only few scholars have actually measured organizational culture in relationship to BPM. Alves et al. (2018) tailored their research towards BPM and used interviews to analyze the extent of BPM values within an organization. In contrast to Alves, Hribar and Mendling (2014) used the Competing Values Framework (CVF), a very traditional and popular instrument to measure organizational culture in general. Additionally, they combined it with an BPM adoption analysis. Their findings show that of the four CVF culture types, the clan culture correlates best with a high level of BPM adoption. However, the hierarchy culture, which can be assumed to be dominant in public administration (Calciolari et al. 2018; Cameron and Quinn 2011; Grau and Moormann 2014), was found to be connected to the lowest level of BPM adoption. The study of Indihar Štemberger et al. (2018) followed a similar approach and also applied the CVF to analyze the relationship between different organizational culture types, introduction strategies and BPM adoption success.

A quite different approach was chosen by Schmiedel et al. (2014) who did not refer to an existing framework on organizational culture to investigate BPM culture but developed a completely new instrument that specifically focusses on BPM culture. They define BPM culture as "an organizational culture that supports BPM" (Schmiedel et al. 2014) and developed an instrument to measure this support. With a global Delphi study (Schmiedel et al. 2013), four BPM values were identified that best capture BPM culture within organizations: customer orientation, excellence, responsibility, and teamwork. Each value in turn consists of two so-called BPM culture dimensions that serve as basis for our study. These eight BPM culture dimensions, their respective BPM values and definitions of the values are presented in Table 1. Schmiedel et al. (2014) operationalized the eight dimensions of BPM culture with a total of 40 survey items, the BPM Culture Assessment, on which this study's empirical analysis is based.

During the preparation of this article's study, we carefully tested both the CVF and the instrument of Schmiedel et al. (2014) in a pilot study (Kregel 2018). We found the CVF to be too general and with limited insights. The CVF allows for the analysis of an organizational culture by classifying an organization proportionally into four standard culture types: clan, adhocracy, hierarchy, and market culture. These culture types, however, are too broad to capture the specifics of BPM values and only deliver limited insights in relation to BPM topics. In direct comparison, the BPM Culture Assessment was able to deliver more informative value and provide a better analysis of different cultural aspects related to BPM.

\subsection{Connecting BPM Culture to Public Management Theory}

The BPM Culture Assessment was developed with the goal of cross-sector validity. However, public administration differs from private sector organizations in many ways (Lyons et al. 2006; Marschollek and Beck 2012), for example with regard to BPM and organizational culture (Syed et al. 2018). While many private sector organizations have been surveyed for the instrument validation, only very few public servants found their way into the sample (Schmiedel et al. 2014). Thus, a perfect fit of the instrument in the public sector context is not per se given. This section gives a brief overview of how the eight BPM culture dimensions could be shaped in a public sector context and highlights major differences to private organizations regarding BPM culture.

The first BPM value "customer orientation" is differentiated into the two BPM culture dimensions internal and external customer orientation. Both dimensions prevail in the public sector though to differing degrees. Although customer orientation is a well-known concept in public management literature, the stakeholders and customers can be quite different from those in the private sector, which is why the term "customer" has not been without critique (Jos and Tompkins 2009). Scholars mainly point out that those who interact with public administration commonly assume many different roles in interactions with public bodies. These range from being customers who passively consume a service to being co-producers of services and citizens who are actively involved in public services delivery (e.g. Distel and Lindgren 2019; Jos and Tompkins 2009; Thomas 2013). Similarly, businesses interacting with public administration can be customers but interact also as taxpayers and increasingly also as co-producers of services. Nuances of these kinds ultimately lead to expectations held by stakeholders that are different from those of private sector customers. These differences mainly refer to performance and value integration on both the public administration's and the public's side that need to be considered when using the term customer in a public sector context 
Table 1 Eight BPM culture dimensions and corresponding BPM values (Schmiedel et al. 2014)

\begin{tabular}{lll}
\hline BPM culture dimensions & BPM value & Definition (Schmiedel et al. 2014) \\
\hline $\begin{array}{l}\text { External customer } \\
\text { orientation }\end{array}$ & $\begin{array}{l}\text { Customer } \\
\text { orientation }\end{array}$ & The proactive and responsive attitude towards the needs of process output recipients \\
$\begin{array}{l}\text { Internal Customer } \\
\begin{array}{l}\text { Orientation } \\
\text { Continuous improvement }\end{array}\end{array}$ & $\begin{array}{l}\text { Excellence } \\
\begin{array}{l}\text { Annovation } \\
\text { Commitment }\end{array}\end{array}$ & $\begin{array}{l}\text { The orientation towards continuous improvement and innovation to achieve superior process } \\
\text { performance }\end{array}$ \\
$\begin{array}{l}\text { Formal structures } \\
\text { Informal structures }\end{array}$ & Teamwork & The commitment to process objectives and the accountability for process decisions \\
\hline
\end{tabular}

(Jos and Tompkins 2009). Consequently, there are different types of typical external customers of local governments and they frequently interact with public administration in more than one role. Internal customers also form a critical element of BPM that often gets less attention. Processes commonly pass through different organizational units until they reach their final customer and end point. The internal customer dimension is analyzed in an effort to shed light on the multi-unit process chain, exchange of information and quality of cooperation. In public administration, due to its strong hierarchical organization, the silos of separated departments are more common. Improvements therefore can be restricted locally and the communication and exchange across the units can be too scarce (Weerakkody et al. 2011). These hierarchies and silos can lead to a weak internal customer orientation, which also typically influences another BPM culture dimension, the innovation capabilities (Hurley and Hult 1998; Salge and Vera 2012).

Many process improvement philosophies and methodologies, such as Lean Management, Total Quality Management and Six Sigma, also include customer orientation as a key concept (Detert et al. 2000; Vanwersch et al. 2016). Together with innovation, continuous improvement forms the second BPM value, "excellence". The combined analysis of both dimensions is known as organizational ambidexterity (Benner and Tushman 2003; Raisch et al. 2009), the importance of which is also discussed for public sector management (Gieske et al. 2020a, b). Process innovation is one of the major innovation types identified in the public management literature (de Vries et al. 2016; Walker 2014). When pursuing innovation strategies, managers must consider the organizational culture to choose either innovation or imitation strategies (Naranjo-Valencia et al. 2011). Typical barriers for innovation in public administration include short-term planning horizons, poor skills in change management, few incentives for innovation, and a culture of risk aversion (Albury 2005). Public administration institutions that encourage experiments, motivate improvements and maintain regular feedback and discussions seem to have a significantly higher likelihood of successful innovations (Demircioglu and Audretsch 2017). The importance of continuous improvement for the public sector has long been known (Berwick 1989) and has been a constant issue in the debates on public sector reforms. The term "continuous improvement" is used in different contexts and with different meanings. In this study's context, we use the definition of Bhuiyan and Baghel (2005), considering continuous improvement "as a culture of sustained improvement targeting the elimination of waste in all systems and processes of an organization". Many projects using continuous improvement methods (e.g. Lean Management or Lean Six Sigma) fail in the public sector when they do not consider sector-specific characteristics, such as organizational culture and business logic (Kregel and Coners 2018; Radnor and Osborne 2013). Especially radical organizational changes lead to strong resistance within public administration (McNulty and Ferlie 2004). For this reason, recommendations for successful continuous improvement in public administration include top management support, the provision of training and creation of a supportive organizational culture (Fryer et al. 2007).

The BPM value "responsibility" is represented by the two BPM culture dimensions "accountability" and "commitment". The respective concept of organizational commitment can be divided into three major forms for showing an employee's attitude (Meyer and Allen 1991). For our study, the affective commitment is the most important, describing the "relative strength of an individual's identification with and involvement in a particular organization" (Mowday et al. 1979). For the public sector, a positive influence of its special characteristics, such as a safe environment, could be found for continuance and normative commitment, but no significant effect on the affective 
commitment was shown (Suzuki and Hur 2020). In contrast, the findings of Boyne (2002) describe a lower organizational commitment in the public sector than in the private sector.

Accountability is prominently analyzed in public management literature and can be discussed with manifold foci (Mulgan 2000). With regard to BPM culture, this dimension targets the stakeholders to account for process performance, which in our context includes process owners, managers and the managing board. A study of Boyne (2002) concludes that public sector managers tend to be less materialistic than their private sector counterparts and therefore could be less motivated by financial rewards, such as performance-related pay. Managerial reforms in European countries are often targeted at "increase[ing] efficiency, responsiveness and accountability of public managers" (Romzek 2000). These targets include management of results, a higher importance of performance measurement, and the question of managerial autonomy (Bezes and Jeannot 2018). How to identify the right goals and motivate and steer managers in the right directions is discussed critically in the literature, reporting that ideas from the private sector often do not lead to the best results (Heinrich 2002; Lewandowski 2019).

The fourth and last BPM value is "teamwork" and consists of the BPM culture dimensions "formal structures" and "informal structures" for collaboration. Management practices such as New Public Management have tried to shift public administration more into entrepreneurship-thinking and private sector types of weaker and more flexible hierarchies. Despite these efforts, strong hierarchies are still a major characteristic of public administration (Diefenbach and Sillince 2011; Raharjo and Eriksson 2017). Formal and informal structures can be differentiated, but both are essential for a functioning organization. For the BPM culture perspective, the collaboration between different organizational units is especially important. Many processes cut across several units and can only be managed in the best way if the complete process can be analyzed and improved from end-to-end. Formal structures include creating cross-functional goals and conducting meetings to discuss shared topics, coordinating tasks and sharing knowledge. Aspects of informal structures include the collaboration with colleagues from other organizational units and institutions as well as the individual's identification with them (Schmiedel et al. 2014). In our application within municipal administration, this aspect focuses on the collaboration between different teams and departments and typically includes a range from feeling like a "family" to autonomous units that barely communicate and collaborate with others. It can also include building networks with partners outside of the own institution to achieve higher performance (Berardo 2009).
High-quality workplace relationships have also been observed to increase commitment to the organization which demonstrates a link to the commitment dimension (Caillier 2017).

We therefore conclude that all eight BPM culture dimensions are relevant to public administration as well. However, their manifestation may vary from that in private sector organizations. At times, these differences may be considerable as the discussion on the customer-orientation in public administration as a specific industry context (vom Brocke et al. 2016) exemplarily shows. The different manifestation of the eight BPM culture dimensions in public administration, as discussed from a theoretical perspective in this section, needs to be translated to the empirical assessment of BPM culture (see Sect. 3).

\section{Research Methodology}

In this section, we present our research design and methodology. Before using the instrument, we evaluated it with regard to its suitability for public administration and, where necessary, adapted it to this specific context (vom Brocke et al. 2016, see Sect. 3.1). We then provide details on the data collection and analysis (Sect. 3.2).

\subsection{Instrument Refinement}

Public administration differs substantially from private organizations in many respects. Researchers have identified four general differences that pertain to the environment in which public and private organizations operate, their respective goals, to structural differences and to differences in managerial values (Boyne 2002). In particular, public administration's structures are reported to be more bureaucratic and allowing for less managerial autonomy (Boyne 2002). Moreover, public administration is less driven by values for money and instead more focused on the public good, while at the same time showing less organizational commitment. Thus, the original instrument needed to be evaluated regarding its fit to the public sector context. Schmiedel et al. (2014) operationalized the eight dimensions of BPM culture with 40 items, five per dimension. In addition, we decided to add questions capturing the public sector context (vom Brocke et al. 2016; vom Brocke et al. 2021). The necessary refinements of the instrument and its contextualization with our additional questions were undertaken in several iterations.

First, the forty original items were individually discussed with four experienced information systems and e-government researchers and furthermore with two public servants to better understand current realities in public administration regarding process management and 
organizational culture. In both cases, we went through the list of items and discussed each one. Additionally, we reviewed the overall structure of the survey. The feedback from both discussion meetings was recorded in form of protocols and subsequently qualitatively analyzed regarding the question of how representative and comprehensible the culture-related items and other questions are for the public sector context. Only then were results from both analyses compared and consolidated; the insights served as basis for the next iteration in our refinement process.

Second, as a result of the experts' feedback and its subsequent analysis, the questionnaire was amended with the additional context-related questions. Specifically, we included questions regarding the respondents' employment status, their professional experience and their perceptions of process management in their organization in general. Our experts highlighted the need to better differentiate the respondents based on their status within the organization and their professional experience since these aspects may impact the respondents' perceptions of BPM culture. More importantly though, we added informational texts, which were not included in the instrument as designed by Schmiedel et al. (2014), on how the questionnaire should be filled out and included explanations of the terms business process and business process management as these are less commonly used in public administration.

Third, the resulting draft of the survey was pre-tested with a selected group of participants from a German municipal administration $(n=43)$, representing ten different departments in total with an emphasis on the organizational and personnel department. The aim of this step was to gather more information on the comprehensibility of items and the overall representativeness of the survey instrument for the public sector because some of the items refer to organizational structures that characterize for-profit organizations, such as reward systems and opaque salary structures, that may not represent public sector realities. Thus, in addition to the closed questions of the BPM Culture Assessment, respondents of our pilot study were provided the opportunity to give detailed feedback on the formulation of items, their accuracy of fit to the public sector and other aspects for improvement. The data set was analyzed with regard to the overall distribution of answers as well as the scales' reliability using Cronbach's alpha (see Anonymized 2018). More importantly, though, we analyzed the textual feedback of the 43 respondents which highlighted difficulties with some of the used terms. In particular, the respondents criticized the use of customer, business process, business process management and best practice in the original culture-related items. Although this version of the instrument already included a short explanation for business process and business process management, the use of the word business seemed to trigger a private sector orientation of the survey in the respondents' perception. Moreover, respondents felt unable to assess the items for the whole organization or the whole department as public administration institutions tend to be rather large and fragmented even in small municipalities.

Fourth and finally, as a result of this pilot study, five of the more general context-related questions, such as employee contract types, were dropped as they turned out to be irrelevant. Therefore, only questions regarding the respondents' professional experience measured by years, their current responsibility within their organization and their field of work were retained.

Moreover, we decided to change the reference of all original culture-related items from organization and $d e$ partment to organizational unit as the test respondents had pointed towards the strong departmentalization and diversity of their institutions. For example, employees of a youth welfare office would hardly be able to evaluate the culture of distanced departments such as building and living or safety and order. With this perspective, we followed the view of Hickson et al. (1971) to assess intra-organizational power and decisions as being highly influenced by organizational sub-units. Additionally, the wording of all culture-related items was changed from business process to either administrative process or simply process. Sometimes, single words such as process colleague and best practices needed an explanation that was added in brackets to the item.

Finally, some respondents noted that many items are clearly geared towards structures of the private sector and reduced the understandability of the survey. Therefore, we decided to retain the informational texts on processes and process management and to also include the concept organizational unit in these texts. In Table 2, we provide examples of the information texts that were added and of how we adapted items.

The first part of the final survey aims at capturing the specific context, i.e., the public sector, and consists of items measuring independent variables with a potential influence on the eight dimensions of BPM culture. These are the classification of the participant's work field into standardized categories such as internal administration, youth and family aid or building and housing. Further questions address the number of years the participants have worked in their current role, in their current organization and in public administration in general (professional experience). The second and main part of the survey contains the adapted BPM culture items (Schmiedel et al. 2014) and consists of eight blocks with five items each to measure an organization's cultural support for the external and internal customer orientation, continuous improvement, innovation, accountability, commitment, formal structures and informal structures (see Table 1). 
Table 2 Examples of changes undertaken in relation to the original instrument

\begin{tabular}{ll}
\hline Original survey (Schmiedel et al. 2014) & Adaptation \\
\hline $\mathrm{n} / \mathrm{a}$ & $\begin{array}{l}\text { Example of an information text (What is a process?) } \\
\text { As a process we understand the content-related, chronological and logical sequence of } \\
\text { activities that are necessary to process an organizationally relevant object. In this case, } \\
\text { objects can be, for example, applications or invoices that you receive and are processed } \\
\text { by you or your colleagues. According to this understanding, a process includes all } \\
\text { typical work procedures in a public administration, for example, the entire application } \\
\text { from receipt to approval of the application. It is not only about the entire process, but } \\
\text { also about sections, for example, the examination of the content of an application }\end{array}$ \\
$\begin{array}{l}\text { Continuous improvement } \\
\text { Continuous improvement }\end{array}$ \\
$\begin{array}{l}\text { Our organization regularly implements best practices } \\
\text { that improve business processes }\end{array}$ \\
$\begin{array}{l}\text { improve processes } \\
\text { ? The term best practice, also known as success method, success model or recipe for } \\
\text { success, comes from Anglo-American business administration and describes proven, } \\
\text { optimal or exemplary methods, practices or procedures in a company }\end{array}$ \\
\hline
\end{tabular}

\subsection{Sample Design}

All items were measured on a 7-point scale, ranging from 1 (total disagreement) to 7 (complete agreement). For each item, respondents were provided with the opportunity to skip an item and choose the option, "I cannot answer this question". Participation in the survey was voluntary and completely anonymous.

The adapted instrument was programmed as an online survey and distributed amongst seven municipalities in Germany's most populous state, North Rhine-Westphalia. The participating municipalities were selected using convenience sampling, varied in size and included municipalities with a central function in their region as well as smaller ones in more rural areas. While convenience sampling is not without critique, the chosen approach is considered appropriate as this research aims at proposing relationships rather than testing hypotheses (Pinsonneault and Kraemer 1993). We based our decisions on suggestions by Speklé and Widener (2018), who argue that for the purpose of generalizing to theory (Lee and Baskerville 2003) - which is this study's aim - rather than to a given population, representative samples are not necessary. However, a convenience sampling strategy needs to account for potential errors in coverage and non-response.

To address these issues, instead of distributing the survey randomly across the whole public sector, we contacted chief information officers, chief digitalization officers and operations managers of various municipalities and asked them to distribute the survey within their organizations. This approach was based on reflections by King and $\mathrm{He}$ (2005) on how to overcome potential coverage errors that may occur in convenience sampling. This way, we were able to collect the opinions of employees of several organizational units, which we deemed necessary as we are interested in phenomena observable at the level of organizations and organizational units, wherefore having respondents from a few selected organizations is desirable (Pinsonneault and Kraemer 1993). Furthermore, the close collaboration with selected managers enabled us to gather a considerable number of responses from employees with various backgrounds and different levels of responsibility. As this research is rather explorative, we were interested in collecting perceptions and opinions of as many different employees as possible rather than creating a representative sample. The variety of administrative units, with a varying degree of responsibility and a varying degree of citizen contact is important to this study as organizational culture in general and BPM culture in particular refer to values shared and shaped by all employees.

\subsection{Data Analysis}

In total, we gathered 733 fully answered surveys. However, the number of respondents for each municipality varied considerably (see Table 3).

Table 3 Participating municipalities

\begin{tabular}{lccr}
\hline & Inhabitants (rounded) & Respondents & Percent \\
\hline Municipality 1 & 250,000 & 244 & 33.3 \\
Municipality 2 & 190,000 & 139 & 19.0 \\
Municipality 3 & 75,000 & 123 & 16.8 \\
Municipality 4 & 30,000 & 43 & 5.9 \\
Municipality 5 & 310,000 & 129 & 17.6 \\
Municipality 6 & 30,000 & 34 & 4.6 \\
Municipality 7 & 50,000 & 21 & 2.9 \\
Total & & 733 & 100.0 \\
\hline
\end{tabular}


Although the survey instrument was already tested by Schmiedel et al. (2014) and in our project tested with a pilot study, we decided to check the scale's reliability again with our final sample due to the changes undertaken and the new context in which the instrument was applied. The reliability analysis indicates robust results with Cronbach's alpha ranging between $\alpha=0.719$ (responsibility) and $\alpha=0.854$ (innovation). All items, scales and alpha values are reported in the appendix (available online via https:// link.springer.com).

The data set was analyzed using descriptive statistics, multivariate analysis of variance (MANOVA) and, as a follow-up analysis, discriminant analysis (DA). The original model proposed by Schmiedel et al. (2014) - designed to benchmark an organization's culture - is reflective-formative and, thus, requires the use of analysis methods such as structural equation modelling. In contrast, this article seeks to explore BPM culture in public administration by describing the nature of each of the BPM culture dimensions (first-order constructs). Then, we aim at understanding which factors potentially determine these dimensions. Instead of benchmarking or comparing single organizations - as suggested as a practical use case by Schmiedel et al. (2014) - this analysis aims at exploring whether the eight dimensions of BPM culture differ with regard to certain external and structural variables that are detached from, for example, managerial decisions or the individuals' skills and attitudes. Conducting MANOVAs for the relationships of interest was deemed an appropriate procedure because we are mainly interested in finding group differences, for example differences between medium sized and small cities. In order to better understand the potential relationships between the dimensions of BPM culture and other variables, we decided to follow this step with DAs. While MANOVA can reveal statistically significant differences between groups based on means, DA can reveal the variables on which these groups differ (Field 2009; Tabachnick and Fidell 2007). Thus, we are not only able to identify relevant antecedents to BPM culture, but also highlight the dimensions on which BPM culture probably differs for certain groups. Both analyses require several assumptions to be met (see Field 2009; Tabachnick and Fidell 2007). Here, we report only on those that either were not considered or that turned out to be problematic. We checked whether values in our data set were missing completely at random using Little's test, which turned out to be significant $\left(\mathrm{Chi}^{2}=11,320,710 ;\right.$ DF10703; $\left.p<0.000\right)$. Thus, missing data in the data set may cause problems. To address this issue and in order to reduce the influence of missing values, we decided to impute these values. As they were scattered through cases and variables, deletion of single cases was deemed ineffective. The mean imputation was not based on means for the whole sample, because the dataset is made up of respondents from various municipalities. Instead, we decided to replace values with means from the respective municipality from which the affected cases originated. Tabachnick and Fidell (2007) also hint researchers at the problem of unequal sample sizes. However, this issue is of lesser importance in our study as our groups occur naturally - as opposed to experimental groups - and, thus, we formed the sub-groups used in our analyses based on quartiles, wherefore they all have similar sample sizes.

Using Mahalanobi's Distance, we detected five multivariate outliers in our sample, which may also impact the results of both analyses. These cases could be excluded from further analyses. Before reducing the size of the sample through this step, we decided to run all analyses with and without outliers and compared the results for substantial differences. As these did not occur, the analyses reported in Sect. 4 are based on the full sample $(n=733)$.

Finally, we needed to decide on a criterion to test the significance of our effects. Commonly, four statistics are provided by current statistic software, i.e., Pillai's trace, Wilk's lambda, Hotelling's trace and Roy's largest root. Of these, the first one is deemed to be the most robust, especially in cases where assumptions for MANOVA are not perfectly met (Tabachnick and Fidell 2007), wherefore we use this value to test the significance of our main effects.

We did not test several independent variables in one model but decided to run several MANOVAs to better estimate the influence of particular variables on the dimensions of BPM culture in public administration. For the eight BPM dimensions, mean-based indices were calculated and used as variables in these analyses. We tested group differences for relationships between the employees' work experience, their responsibility and the size of the municipality on the one hand and the eight BPM culture dimensions on the other hand. Research on BPM and change in public administration suggests that these organizations are strongly shaped by rigid hierarchies and formal structures (e.g. Indihar-Štemberger and Jaklič 2007). Thus, we assume that a long experience within the public sector increases employees' obedience to these structures and, thus, their assessment of the BPM culture dimensions. Furthermore, scholars argue that employee turnover may "generate fresh viewpoints and broaden the experiences of key personnel" (Meier and Hicklin 2008). The obedience to hierarchical structures, thus, may become even more pronounced when employees are members of the same organization for a long time. As such, we assume that not only the affiliation with the public sector in general but also the experiences with one particular administration and one particular role within the organization impact the employees' assessment of the BPM culture dimensions. We measured the employees' respective experience in 
terms of the years they have worked in the public sector, in their current organization and in their current role. Repeatedly, authors point to the importance of managers' role in and commitment to organizations and change processes (e.g. Indihar-Štemberger and Jaklič 2007; Peccei et al. 2011). Thus, we assume that employees with more responsibility assess the BPM culture dimensions differently than employees with less or no management responsibility. Finally, we test whether the size of the municipality (in terms of its inhabitants) has a relationship with the public sector employees' assessment of the eight BPM culture dimensions. The organization size in has been identified in previous studies as an important contextual factor for process performance, process awareness, quality, innovation and the adoption of e-government (Jayaram et al. 2010; Knott and Vieregger 2020; Moon and Norris 2005; Ongena and Ravesteyn 2020).

\section{Results}

The following sections report the results of our data analysis. The first section sheds light on the applicability of the instrument in the public sector (addressing RO1), whereas Sect. 4.2 describes the nature of the eight dimensions of BPM culture for the surveyed public administration. In Sect. 4.3, we explore which factors might impact these dimensions in public administration (addressing RO2).

\subsection{BPM Culture Assessment for the Public Sector}

The first research objective is partly achieved by adapting the overall setting, formulation of specific items and the introduction of examples and explanations within the questionnaire to better guide the respondents through the survey. Despite the changes applied to the instrument after interviewing public sector experts, the descriptive analysis of our final sample revealed that one construct in particular caused problems. The dimension internal customer orientation stands out due to the high number of missing values. One item was particularly striking with a total of $27.4 \%$ of the answers missing ("Our organization defines internal customers for all processes"). The other items also showed an above average number of missing values (more than $13 \%$ ). In order to better understand why so many respondents were unable to assess this dimension, open comments collected after each block of items were analyzed and reveal several content-driven reasons for this observation. These reasons and consequences of the high number of missing values on the dimension internal customer orientation are discussed in detail in Sect. 5.
4.2 Summarizing the BPM Culture in Public Administration

To present the descriptive results of the study and create a picture of the overall nature of BPM culture in public administration, we follow the suggestions by Schmiedel et al. (2014) for this kind of evaluation. The first part of the study includes questions about job characteristics and participants' experience. The largest groups of participants are formed by the following fields of work: Internal Administration (22\%), Children, Youth and Family Support $(16 \%)$, Safety and Order $(12 \%)$ and Housing and Urban Development (10\%). On average, the respondents showed a slight tendency towards more operational roles within their organizations (mean: 3.47, median: 3, min: 1, max: 7). When asked about the frequency of contact with citizens, companies or other external stakeholders, $47 \%$ stated they had contact to them on a daily basis. With a mean of 5.21 (median: 6) on a scale from never (1) to daily (7), a large majority of the participants had very regular contact with external stakeholders. When looking at the median values, the average study participant works for 21 years in public administration, for 12 years in the current institution and for 5 years in the same job role.

The results of the eight BPM culture dimensions for all 733 survey participants are summarized in Fig. 1. The mean values for the BPM culture dimensions range between 3.57 for continuous improvement and 4.34 for external customer orientation. The overall results for all municipalities show that the participants tend to evaluate the customer orientation and teamwork values more positively than the others. However, the excellence value, including innovation and continuous improvement, in comparison, received the lowest evaluations. We also compared the different municipalities with each other (see Fig. 2) and will take up this topic in the discussion section.

\subsection{Determinants of the Dimensions of BPM Culture in Local Governments}

The second research objective is to identify possible determinants of the dimensions of BPM culture in municipal administration.

The first relationship we tested is between the BPM culture dimensions (dependent) and the number of years an employee has been active in the public sector. We asked the respondents to estimate the number of years they have been working in the public sector (see appendix) and then formed four roughly equally sized groups using the quartiles to define the groups.

There was a significant effect (Pillai's trace) of years in the public sector on the dimensions of BPM culture, $V=0.076, \quad F(24,2154)=2.33, p<0.001$. However, 
Fig. 1 BPM culture spider web diagram based on all participants' data
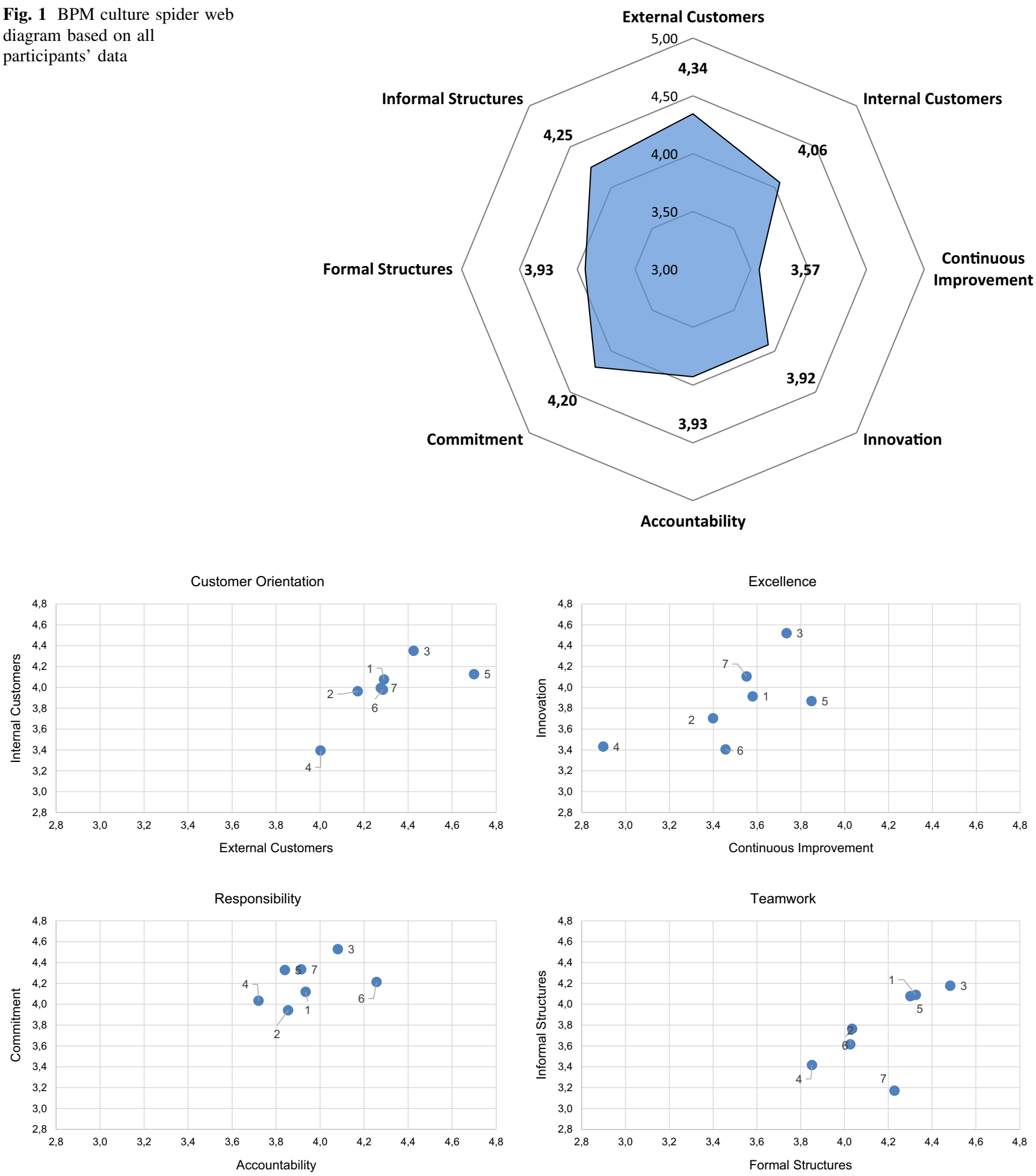

Fig. 2 Dimension comparisons between the participating municipalities

separate univariate ANOVAs on the outcome variable (BPM culture dimensions) revealed non-significant effects for all but three BPM culture dimensions, namely innovation, $F(3,723)=3.4, p=0.017$, continuous improvement, $F(3,723)=3.0, p=0.03$ and internal customer orientation, $F(3,723)=2.8, p=0.04$. The follow-up DA revealed three discriminant functions, of which the first explained $76.9 \%$ of the variance (canonical $\mathrm{R}^{2}=0.058$ ). The three discriminant functions together differentiate the 
groups (i.e. the number of years spent in the public sector), with $\Lambda=0.925, \chi^{2}(24)=55.9, p<0.001$.

The structure matrix (see Table 4) suggests that innovation and continuous improvement (the excellence dimension) highly correlate with the first variate, whereas the second variate correlates highly with internal customer orientation and commitment and the third correlates highly with informal structures. These variables presumably are the best predictors for distinguishing employees with less experience from those with more experience. Finally, we also considered the group centroids plotted in Figure A1 (Appendix), indicating that the employee group with the least experience (up to 7 years of experience) is discriminated by variate 1 (i.e., by the excellence dimension), and group 2 (up to 21 years of experience) is discriminated by variate 2 (i.e., by internal customer orientation and commitment) from the other groups.

The second relationship we tested was between the BPM culture dimensions (dependent) and the number of years an employee has been working in the current organization. Again, we asked the respondents to estimate the number of years they have been working in their organization and then formed four roughly equally sized groups using the quartiles to define the groups. There was a significant effect of years spent in the organization on the BPM culture dimensions, $V=0.067, F(24,2154)=2.035, p<0.01$. However, separate univariate ANOVAs on the outcome revealed non-significant effects for all but two dimensions, namely formal structures, $F(3,723)=2.792, p<0.05$ and internal customer orientation, $F(3,723)=4.03, p<0.01$. Again, this analysis was followed by a DA, which revealed

Table 4 Structure matrix for the BPM culture dimensions and employees' experience in the public sector

\begin{tabular}{llll}
\hline Structure matrix & \multicolumn{3}{l}{$l$} \\
\hline & \multicolumn{4}{l}{ Function } & \\
\cline { 2 - 4 } & 1 & 2 & 3 \\
\hline Innovation & $.457^{*}$ & .285 & .263 \\
Continuous improvement & $.445^{*}$ & .091 & -.202 \\
Internal customer orientation & .359 & $.517^{*}$ & .083 \\
Commitment & .298 & $.494^{*}$ & -.204 \\
Accountability & -.259 & $.359^{*}$ & .274 \\
Formal structures & -.291 & $.311^{*}$ & -.152 \\
External customer orientation & .222 & $-.306^{*}$ & -.151 \\
Informal structures & .122 & .049 & $.423^{*}$ \\
\hline Poold within-groups correlations & &
\end{tabular}

Pooled within-groups correlations between discriminating variables and standardized canonical discriminant functions

Variables ordered by absolute size of correlation within function

*Largest absolute correlation between each variable and any discriminant function three discriminant functions of which the first explained $67.9 \%$ of the variance (canonical $\mathrm{R}^{2}=0.045$ ). The three discriminant functions together differentiate the groups (i.e., the number of years spent in the public sector), with $\Lambda=0.935, \chi^{2}(24)=48.74, p<0.01$.

The structure matrix (see Table 5) reveals that the first variate and continuous improvement highly correlate. The second variate highly correlates with the dimension internal customer orientation and, to a far lesser degree, also with formal structures. The third variate correlates fairly with continuous improvement and innovation (excellence value).

The group centroids shown in Figure A1 (Appendix) indicate that the employee group with the most experience (more than 26 years) is discriminated by function 2 (internal customer orientation, formal structures), whereas function 1 (continuous improvement) discriminates the group with the least experience in the public sector.

We also tested whether the number of years in the current role influenced the dimensions of BPM culture, but the MANOVA did not suggest such an influence $(V=0.045, F(24,2154)=1.373, p>0.05)$.

Next, we analyzed whether the employee's function from a purely operative function to being in a purely leading role had an influence on the BPM culture dimensions. There was a significant effect of an employee's function on BPM culture dimensions, $V=0.103, F(16$, $1412)=4.786, p<0.001$. Separate univariate ANOVAs on the outcome, revealed only two non-significant effects for accountability and formal structures. Thus, the contrasts also show significant group differences for those

Table 5 Structure matrix for the BPM culture dimensions and employees' experience in the respective organization

Structure matrix

\begin{tabular}{llll}
\hline & \multicolumn{2}{l}{ Function } & \\
\cline { 2 - 4 } & 1 & 2 & 3 \\
\hline Continuous improvement & $.423^{*}$ & .174 & .395 \\
External customer orientation & $.063^{*}$ & .011 & -.049 \\
Internal customer orientation & .336 & $.830^{*}$ & -.063 \\
Formal structures & -.374 & $.524^{*}$ & .299 \\
Commitment & .271 & $.360^{*}$ & .127 \\
Innovation & .353 & .228 & $.376^{*}$ \\
Accountability & -.233 & .338 & $.360^{*}$ \\
Informal structures & .106 & .228 & $-.330^{*}$ \\
\hline
\end{tabular}

Pooled within-groups correlations between discriminating variables and standardized canonical discriminant functions

Variables ordered by absolute size of correlation within function *Largest absolute correlation between each variable and any discriminant function 
employees with operative roles as compared to those in positions with more responsibility for all dimensions but accountability and formal structures. The same pattern can be observed when comparing those employees in leading positions with those employees with medium responsibility, except that there are two further non-significant differences for internal customer orientation $(p=0.287)$ and commitment $(p=0.071)$.

The follow-up DA revealed two discriminant functions of which the first explains $78.5 \%$ of the variance (canonical $\left.\mathrm{R}^{2}=0.079\right)$ and the second $21.5 \%$ of the variance (canonical $\mathrm{R}^{2}=0.023$ ). Both functions together differentiate the groups significantly $\Lambda=0.899, \chi^{2}(16)=75.467$, $p<0.001$ and $\Lambda=0.98, \chi^{2}(7)=16.612, p<0.05$.

The structure matrix (Table 6) reveals that the first variate and innovation highly correlate. Lower but still considerable correlations occur for continuous improvement, informal structures and external customer orientation. The second variate correlates highly with external customer orientation, followed by commitment and internal customer orientation. As shown in Figure A1 (Appendix), function 1 (innovation, informal structures, external customer orientation) discriminates the employees in leading positions from those with less responsibility, whereas the second function (external customer orientation, commitment, internal customer orientation) discriminates the second group with medium responsibility. Within public administration, these are employees leading smaller teams while at the same time reporting to a higher hierarchy level.

Table 6 Structure matrix for the BPM culture dimensions and employees' responsibility in the organization

\begin{tabular}{lll}
\hline Structure matrix & & \\
\hline & \multicolumn{1}{l}{ Function } & \\
\cline { 2 - 3 } & 1 & 2 \\
\hline Innovation & $.750^{*}$ & -.110 \\
Continuous improvement & $.582^{*}$ & .381 \\
Informal structures & $.575^{*}$ & -.054 \\
Accountability & $.126^{*}$ & .008 \\
External customer orientation & .564 & $.592^{*}$ \\
Commitment & .423 & $.465^{*}$ \\
Internal customer orientation & .304 & $.444^{*}$ \\
Formal structures & .078 & $.132^{*}$ \\
\hline
\end{tabular}

Pooled within-groups correlations between discriminating variables and standardized canonical discriminant functions

Variables ordered by absolute size of correlation within function

*Largest absolute correlation between each variable and any discriminant function
Finally, we tested whether the size of a municipality (see Table 3 for municipality sizes) has an effect on the dimensions of BPM culture. For this analysis, we built three groups: Group 1 contains municipalities 4, 6 and 7, which are the smallest with 50,000 or fewer inhabitants. Group 2 is made up of municipality 3 with 75,000 inhabitants. Group 3 consists of only municipality 2 with more than 75,000 but less than 200,000 inhabitants. Finally, group 4 comprises the two largest municipalities (1 and 5) with 250,000 and 310,000 inhabitants. The MANOVA and DA were run with these four groups.

There was a significant effect of municipality size on the BPM culture dimensions, $V=0.097, F(24,2154)=3.0$, $p<0.001$. The separate univariate ANOVAs revealed significant effects for all but two dimensions, i.e., $a c$ countability and external customer orientation. The subsequent DA revealed three discriminant functions of which the first explains $54.2 \%$ of the variance (canonical $\left.\mathrm{R}^{2}=0.052\right)$. The second function explains $34.8 \%$ of the variance (canonical $R^{2}=0.034$ ), while the last function explains only $11.0 \%$ of the variance (canonical $\left.\mathrm{R}^{2}=0.011\right)$. The first three functions differentiate the groups significantly with $\Lambda=0.906, \chi^{2}(24)=71.369$, $p<0.001$ and the second and third functions differentiate the groups with $\Lambda=0.955, \chi^{2}(14)=32.927, p<0.01$. The structure matrix (Table 7) indicates that variate one and formal structures, continuous improvement, internal customer orientation and informal structures highly correlate, whereas innovation correlates well with the second variate. The third variate correlates fairly with the dimension commitment.

Table 7 Structure matrix for the BPM culture dimensions and municipality size

Structure matrix

\begin{tabular}{llll}
\hline & \multicolumn{3}{l}{ Function } \\
\cline { 2 - 4 } & 1 & 2 & 3 \\
\hline Formal structures & $.783^{*}$ & -.013 & .358 \\
Continuous improvement & $.563^{*}$ & -.034 & .128 \\
Internal customer orientation & $.543^{*}$ & .257 & -.190 \\
Informal structures & $.541^{*}$ & .154 & .330 \\
External customer orientation & $.388^{*}$ & -.034 & .314 \\
Innovation & .659 & $.665^{*}$ & .027 \\
Accountability & .090 & $.280^{*}$ & .224 \\
Commitment & .335 & .455 & $.577^{*}$ \\
\hline
\end{tabular}

Pooled within-groups correlations between discriminating variables and standardized canonical discriminant functions

* Largest absolute correlation between each variable and any discriminant function

Variables ordered by absolute size of correlation within function 
As evident from Figure A1 (Appendix), function 1 discriminates the municipalities in groups 2 and 4 from groups 1 and 3, whereas the second function discriminates group 2 (medium-sized municipalities) from all other municipalities.

\section{Discussion}

This article set out to explore the BPM culture of municipal administration and its determinants. To this end, we set forth the research question of how and by which determinants is BPM culture in public administration shaped and divided it into three research objectives, which are addressed and discussed in the subsequent sections. Based on this discussion, we furthermore derive an agenda for future research on the topic of BPM culture in public administration and highlight limitations that should be considered when interpreting the findings of this study.

Regarding the overarching research question, our study indicates that BPM culture in public administration is observable, yet some of the dimensions are not exploited to the full extent (see Sect. 5.1 for a more detailed discussion). Furthermore, we find that BPM culture in public administration is influenced by several external variables such as employees' experiences and responsibility (see Sect. 5.2 for a more detailed discussion).

\subsection{Research Objective 1: Applicability of the BPM Culture Assessment Instrument}

In general, we find considerable differences between the participating organizations about their employees' assessment of the eight BPM culture dimensions. Overall, external customer orientation, informal structures and commitment were evaluated comparably positive. The by far lowest score was given to the continuous improvement dimension (see Fig. 1). The remaining dimensions innovation, accountability, formal structures and internal customer orientation were evaluated very averagely. The participating municipalities seem to be able to manage their processes but could adjust their capabilities regarding continuous improvement to create a stronger BPM culture. The average of 4.03 of all eight dimensions taken together demonstrates a quite mixed evaluation of the BPM culture. Even though an ideal BPM culture with maximum values in all dimensions is neither realistic nor reasonable to achieve, the dimension continuous improvement requires particular attention as the currently low ratings might indicate significant challenges for managing the ongoing digitalization (Mendling et al. 2020).

The comparison of the municipalities' BPM cultures exhibits large differences. Municipality 3 with only 75,000 citizens shows one of the most developed BPM cultures with the highest scores on the dimensions innovation and commitment, whereas the largest municipality (municipality 5) evaluates continuous improvement and customer orientation best. Municipalities 4 and 6 have about the same number of citizens but show very different cultures. These large differences lead us to the analysis of BPM culture determinants (the corresponding discussion is presented in Sect. 5.2).

Our objective to apply and test the BPM Culture Assessment instrument by Schmiedel et al. (2014) in the public sector refers to both more formal aspects, such as the understandability of items and terms, and more contentrelated aspects, such as the adequacy of the constructs and items. Regarding the first aspect, discussions with public sector experts and researchers (see Sect. 3.1) revealed that some items had to be rephrased to be better understood by respondents from the public sector. The discussions also showed that BPM-related vocabulary does not necessarily fit the employees' day-to-day professional experiences. Both aspects were also mirrored by the pre-test which we conducted, wherefore we added informative texts to some of the items and slightly adapted their wording. The resulting BPM Culture Assessment for Public Administration was then used in a large-scale online survey. Despite the careful adaptions and the overall fit of the adjusted instrument to the public sector context, the analysis of our final data set revealed a high number of missing values on one dimension, i.e., the internal customer orientation. In order to better understand why this dimension was hard to assess, we examined open comments from the survey respondents. After each set of questions, respondents were given the chance to comment the questionnaire. A closer evaluation of these comments reveals four potential reasons for why the BPM culture dimension internal customer orientation does not entirely fit public sector realities.

(1) Lacking process documentation and process management. Despite the amount of research on process management in public administration (Houy et al. 2010) and an abundance of process management initiatives in these organizations, many respondents declared that processes were neither documented nor properly managed in their organizations and organizational units. For example, one respondent stated that "Instructions or flowcharts [for processes] are largely unknown to me." Taking into consideration that understanding who internal customers are requires the employees to work in properly managed and documented processes (Schmiedel et al. 2013), this could be one explanation for why so many respondents were not able to answer the questions on this dimension.

(2) Frequent, unstandardized process changes. Other respondents reported that in addition to a lack of process 
documentation and management, internal processes tend to be changed frequently (e.g., "My workflows and processes have been subject to constant change since I started working here.”). One explanation for this reaction might be a significant resistance to change (Bannister 2001; IndiharŠtemberger and Jaklič 2007). However, it might also be difficult for public sector employees to properly define who their internal customers are when processes, and thus responsibilities and tasks, are changed without documentation.

(3) Organizational unit too broad and no cooperation across departments. Although we carefully adapted the questionnaire to public administration and discussed and tested the items with public sector experts, some respondents still considered the focus on the organizational unit as too broad. These respondents then stated that instead they answered all questions in relation to their area of responsibility: "In a relatively large municipality it is difficult to get an overview of the processes in other organizational units. There are not always interfaces available or necessary in my role. Furthermore, there are also divisions into subject areas in organizational units. I have therefore answered the questions for my area." This assessment, though anecdotal evidence, is in line with prior research. Public sector reforms such as NPM and the ongoing digital transformation are considered a means to overcome the Weberian bureaucracy paradigm and, thus, the strong departmentalization of public administration (Bannister 2001; Ho 2002; Roberts 2011). However, many public administration institutions are still characterized by strong hierarchies and organizational silos, in particular with regard to digitalization efforts such as the interoperability of systems (Klischewski 2004) and open governmental data (Young 2020).

(4) No recognition and no existence of internal customers. Finally, some respondents referred to internal customers in their comments without recognizing them as such, e.g. "In our unit, no one has contact to customers. Mostly, it's contacts, with the district administration or state ministries.". Others explicitly stated that their organizational unit has no internal customers, e.g. "In my opinion, our unit has no internal customers." and "Our task area includes only external customers.". This pattern highlights a major problem with the instrument: External customers are easily identified as citizens, businesses or even other governmental/administrative agencies, even though the term "customer" might be evaluated as inadequate. This might be interpreted as a result of public sector reforms such as NPM that adapted the private sector logic of conceptualizing citizens as customers (Aberbach and Christensen 2005; Dunleavy et al. 2006; Wynen and Verhoest 2015). In contrast, many employees across all hierarchical levels have difficulties in applying the customer concept to internal stakeholders and recipients of process outputs. As the statements above indicate, this might be due to a lack of appropriate process documentation and management. Furthermore, the analysis of the open comments suggests that the customer logic underlying the original instrument might not reflect public sector realities in that internal customers are not perceived as such but rather as entities of a hierarchy that either prescribe tasks or have to fulfil certain tasks.

While we may conclude that the instrument is generally applicable to the public sector, the high number of missing values on the internal customer orientation dimension has implications for the overall instrument that should be addressed by future research. First, the comparison of the BPM value customer orientation with the other three values becomes more difficult, as the results may be biased. Especially for those employees with only infrequent contact with external stakeholders, the assessment of this BPM value might become difficult. Second, and likely more important, this finding indicates that the traditional customer logic does not fit with the strict hierarchies of public administration and their oftentimes legally driven processes. Third, we find that many municipalities in Germany are just introducing process management to their organizations. Thus, with the increasing professionalization of process management in public administration, understanding who internal customers are might become clearer and more present in the employees' individual perceptions. Therefore, we suggest that the internal customer orientation dimension should continue to be queried, as it is likely that the increasing professionalization of process management in the public sector will result in fewer missing values and a more precise assessment of this dimension by the respondents. But we also suggest to further adapt the instrument and this particular dimension to the public sector, e.g., by not using the word "customer" as is seldomly fits the public administration realities. Furthermore, we deem more information or examples throughout the questionnaire as helpful for respondents to better grasp the dimensions of external and internal customer orientation.

\subsection{Research Objective 2: Exploring Determinants of the BPM Culture Dimensions in Public Administration}

The second research objective was to explore potential determinants of BPM culture in the public sector. We specifically investigated the influence of the employees' experience with the public sector and their responsibility in their organizations on BPM culture. The results indicate that the experience an employee has with the public sector may have an influence on the assessment of BPM culture. However, we see that this influence could be most 
important for the innovation, continuous improvement and internal customer orientation dimensions. The DA suggests that the group separation can be best explained in terms of one underlying dimension. In this context, we assume that this dimension could be the first-year group (those who entered the public sector last). The contrast results obtained through the MANOVA show a significant relationship for years and above listed dimensions when contrasting the first and the last year groups. However, it does not show any significant influence for the other contrasts. Cautiously interpreted, we might assume that the years one has been employed in the public sector might affect the BPM culture. But this relationship is strongest for those with the least experience and highest for the BPM culture dimensions innovation, continuous improvement and internal customer orientation. We therefore propose the following relationships $(\mathrm{R})$ :

$\mathrm{R} 1$. There is a negative relationship between the years one has been employed in the public sector and the perceptions of the dimensions of BPM culture.

R2. Less experienced employees assess their organizations' excellence (innovation and continuous improvement) more positively.

With regard to the effect of employees' experience with their current organization on the assessment of the BPM culture dimensions, our results were less unequivocal. Several scholars confirm the influence of employee turnover on the overall organizational performance (Meier and Hicklin 2008). Wynen et al. (2019) concretized this relationship by analyzing tasks with a high "process conformance" (prescribed standards and rules), an aspect that is very similar to BPM culture. Their results show an inverted U-shaped relationship, summarizing that too high and too low employee turnover negatively affects the organizational performance. Our data suggests that both the employees with the least and the most experience seem to put less emphasis on formal structures than those with medium experience (8-21 years), but not exclusively. The employees with less experience also focus on innovation and continuous improvement, whereas employees with medium to high experience focus on dimensions such as internal customer orientation, commitment and accountability. Against this background, we propose a relationship between employees' experience within an organization and BPM culture assessment. However, more research into this particular relationship is needed regarding both the direction of the effect and the effect for the BPM culture dimensions.

R3. There is a relationship between the employees' experience with their current organization and their assessment of the BPM culture dimensions.
Our findings suggest a relationship between an employee's responsibility and assessment of BPM culture in that leaders in public administration are more focused on the excellence dimension (innovation and continuous improvement) than those employees with less responsibility. Those employees with medium responsibility seem to be more focused on external and internal customer orientation, commitment and formal structures, leading us to propose the following relationship:

R4. There is a positive relationship between the employees' degree of responsibility and their assessment of the BPM culture dimensions.

R5. Employees in leading positions evaluate the organization's excellence (innovation and continuous improvement) more positively than those with less responsibility.

Finally, we analyzed the municipality size (number of citizens) as a potential determinant for BPM culture, as it determines the respective size of public administration and, thus, may have an impact on the assessment of the dimensions of BPM culture. Our results suggest that smaller municipalities significantly differ on most BPM culture dimensions as compared to larger municipalities. However, for the medium-sized municipalities, there is a positive relationship with two dimensions, innovation and commitment, as compared to the larger municipalities. Thus, we propose the following relationship:

\section{R6. Municipality size may impact BPM culture in that employees of smaller municipalities assess the BPM culture dimensions worse than employees of larger municipalities.}

\subsection{Research Objective 3: Proposing an Agenda for Future Research on BPM Culture in Public Administration}

By discussing the results of our analyses in the preceding sections, our study contributes to both IS and public sector research. These contributions are summarized in the following paragraphs in form of an agenda for research on BPM culture in public administration. We demonstrate that our study covered aspects that so far did not receive much scholarly attention and need to be addressed by further research. Thereby, we advance the original work of Schmiedel et al. (2014), first by proposing the BPM Culture Assessment for Public Administration as a means to benchmark and investigate BPM culture in a public sector context; and, second, by uncovering context-sensitive determinants of BPM culture in the public sector. While Schmiedel et al. (2014) focus their suggestions for further research on BPM culture as an independent variable 
influencing other phenomena, we offer insights into how BPM culture is shaped within public administration. Thus, this research can form the basis for both researchers and practitioners to better understand the formation and active management of process-oriented cultures. The contributions of our study are summarized in three central research questions that should be addressed by future research activities (see Table 8 , research agenda).

Firstly, we propose to investigate the question What is the nature of BPM culture in public administration? Our research partially addresses concerns of prior research to better account for the characteristics of public administration in BPM research (Niehaves et al. 2013; Syed et al. 2018) by proposing the BPM Culture Assessment for Public Administration. Yet, there is a clear need for both more theoretical and empirical research in this area. Schmiedel et al. (2014) developed their original framework detached from any specific sector and subsequent research into this topic did not account for context-sensitivity either. However, our work suggests that at least the customer orientation dimensions of BPM culture are of less importance in public administration. The results of our research indicate that public sector employees have difficulties in unambiguously identifying the internal customers of their organizational unit and, more generally, expressed concerns regarding the fit of the customer concept with the public sector context. Thus, the two customer dimensions of BPM culture might not be the most appropriate for a public sector context, neither theoretically nor as operationalized in the BPM Culture Assessment. On the one hand, we see a need for further studies that shed more light on the characteristics of these two dimensions and their overall fit for public administration. These studies should be empirical, quantitative assessments of the actual shape of all BPM culture dimensions in public administration, i.e., benchmarking studies. On the other hand, there is a clear need for more theoretical endeavors that explore potentially relevant, yet unrevealed dimensions that could shape BPM culture in public administration (as opposed to process-oriented culture in for-profit organizations). For example, Syed et al. (2018) argue that with regard to BPM, the culture in public administration is more strongly shaped by its environment than in for-profit organizations, in particular by political decisions. Hence, environment-orientation could be a relevant dimension for BPM culture in public administration.

In addition, there is a need to better reflect public administration as a context in the concept of BPM culture by developing and using sector-specific vocabularies. The influence of the employees' experience with their respective role on their assessment of BPM culture was insignificant. With regard to the early stage of process management in (German) public administration, we assume that most employees do not have a clear understanding of their role within specific businesses processes. Apparently, BPM-related terms such as "role" or "internal

Table 8 Research agenda

Suggested research question

What is the nature of BPM culture in public administration?

What is the impact of BPM Culture within and outside of public administration?
Suggested research activities

Close examination of the customer dimensions of BPM culture in public administration

Quantitative assessment of all BPM culture dimensions in public administration (benchmarking)

At different administrative levels (local, regional, national, international)

In different cultural settings

Theoretical and explorative studies to assess the importance and adequacy of the eight BPM culture dimensions in public administration

Theoretical and explorative studies to uncover further, potentially important dimensions of BPM culture in public administration

Development and use of a public sector-specific BPM vocabulary

What shapes BPM culture in public administration? Quantitative testing of the proposed relationships with cross-sectional data

Qualitative and/or explorative research to uncover further determinants of BPM culture in public administration

Quantitative and/or qualitative assessment of the long-term effects of the determinants on BPM culture with longitudinal designs

Explore the relationship between BPM culture and the digital transformation of public administration

Analyze how BPM culture influences public service delivery

Analyze how BPM culture influences service delivery within public administration

Advance research about integrating BPM culture assessments in BPM maturity models 
customer" are harder to assess in public administration as they - so far - have not been part of the professional canon in these organizations. While terms such as these may become more prevalent with the increasing professionalization of BPM in public administration, we should develop new vocabularies that take into consideration the specific characteristics of public administration and address them adequately.

Secondly, we suggest investigating the question What shapes BPM culture in public administration? As a result of this study, we suggest several determinants that potentially impact BPM culture in public administration, but these determinants need to be tested with further (quantitative) studies as well as with longitudinal research designs. The relationships proposed in this article should be tested with further studies to confirm, refine or reject them. For example, we find a significant contribution of the municipality size to the employees' BPM culture assessment which leads to the assumption that further untested factors play at least an additional role: for example, economic wealth of a municipality, disposability of resources, location and leadership may have a larger influence than municipality size alone.

In order to understand the long-term impacts of our identified and further factors on BPM culture, future research should use multiple points in time to assess the changes in BPM culture. In the context of public administration, Schmiedel et al. (2020) suggest a direct impact of BPM methods on process performance that is only partially mediated by BPM culture and they argue that "the adherence to respective techniques may leave no room for interpretation in contexts that follow strict operating procedures" (p. 9). With the call for and adoption of more agile methods (Mergel et al. 2020) in public administration and the ongoing digital transformation as witnessed in the public sector (Mergel et al. 2019), we assume changes in process management and execution as well and - consequently - a changing role of BPM culture. Whereas this study focusses on external and mostly static variables such as municipality size and employee characteristics, there is a need to consider the formation of BPM culture in relation to other general phenomena such as digitalization or workforce up-skilling as well as in relation to BPM-related phenomena such as BPM maturity. It is reasonable to assume that public administration, with an established tradition of process management also have a BPM culture different from organizations that are just about to introduce or recently introduced professional process management in their organizations (Shafagatova and Van Looy 2021; Van Looy and de Backer 2013). Hence, our finding that employees of smaller administration institutions assess their organizations' BPM culture worse than those of larger institutions might also indicate a difference in their process management maturity. Smaller organizations could have less resources available for the establishment of BPM and an according BPM culture.

Thirdly, we suggest investigating the question What is the impact of BPM culture within and outside of public administration? Schmiedel et al. (2014) proposed future research avenues that mainly address the relationship of BPM culture with an organization's success in terms of increased efficiency. In line with Fischer et al. (2020) and Mendling et al. (2020), we assume a close relationship between BPM and the digital transformation of organizations. The eight dimensions of BPM culture may impact the digital transformation of public administration, for example through a more pronounced customer orientation and an increased focus on process innovation and improvements. Thus, in the context of public administration, it might be worthwhile to also consider how much BPM culture affects service delivery to citizens and businesses, but also how interorganizational service delivery is affected. The interdependency of a distinct BPM culture and digitalization efforts is a promising field of further research and should be addressed both empirically and theoretically.

While the interrelation between BPM culture and digitalization may affect both internal and external service delivery, we also suggest studying the relationship between BPM culture dimensions and BPM maturity within public administration. The effects of changing BPM culture on internal process management and maturity (and: vice versa) might be a considerable element of maturity assessments.

\subsection{Limitations}

This explorative study analyzed data from seven municipalities in one German state. Thus, the results of our study are limited in scope to the German culture and the German administrative system. As we collected data from only one of the federal states, our proposed relationships need to be tested with a broader sample, reflecting the variety of public administration throughout Germany. Any result of this study should be interpreted against this background, and carefully transferred to other contexts. However, despite these limitations, we deem the study's results generalizable to the extent that we propose testable assumptions that can be used both to empirically investigate BPM culture in public administration and to deepen our theoretical understanding of the impact of BPM culture.

Furthermore, we transferred the BPM Culture Assessment instrument and proposed ways to better fit with the overall public-sector context. Again, this transfer is highly context-sensitive in that it addresses peculiarities of the German administrative system. While we show a way to 
transfer the instrument to the public sector and aspects that need to be considered before using the instrument, scholars should carefully consider the country-specific context before applying the changes to the instrument as proposed in this article.

\section{Conclusions}

Our study followed an overarching research question and three detailing research objectives. First, we tested the BPM Culture Assessment instrument for its applicability in a public sector context. We distributed our survey to seven German municipalities and received 733 completed questionnaires. Most parts of the instrument proved applicable, but we also identified that the items for internal customer orientation led to many missing answers and low reliability. Our second objective was to analyse determinants for the BPM culture. Based on the data analysis, we suggest that employees' experience, their responsibility and the municipality's size are all determinants of BPM culture in public administration. Finally, we generated an agenda for research on BPM culture in public administration that highlights a need for additional, for in-depth, and for theory-driven research into this matter.

The results of this study are an important contribution to both research on BPM and research on public administration as it advances our understanding of how BPM is shaped by an organization's culture. The study also highlights differences between the public and private sectors that have to be addressed when implementing BPM in public administration.

Funding Open Access funding enabled and organized by Projekt DEAL.

Supplementary InformationThe online version contains supplementary material available at https://doi.org/10.1007/s12599021-00713-z.

Open Access This article is licensed under a Creative Commons Attribution 4.0 International License, which permits use, sharing, adaptation, distribution and reproduction in any medium or format, as long as you give appropriate credit to the original author(s) and the source, provide a link to the Creative Commons licence, and indicate if changes were made. The images or other third party material in this article are included in the article's Creative Commons licence, unless indicated otherwise in a credit line to the material. If material is not included in the article's Creative Commons licence and your intended use is not permitted by statutory regulation or exceeds the permitted use, you will need to obtain permission directly from the copyright holder. To view a copy of this licence, visit http://creativecommons. org/licenses/by/4.0/.

\section{References}

Aberbach JD, Christensen T (2005) Citizens and consumers: an NPM dilemma. Public Manag Rev 7:225-246. https://doi.org/10.1080/ 14719030500091319

Albury D (2005) Fostering innovation in public services. Public Money Manag 25:51-56. https://doi.org/10.1111/j.1467-9302. 2005.00450.x

Alves C, Jatobá I, Valença G, Fraga G (2018) Exploring the influence of organizational culture on BPM success: the experience of the Pernambuco Court of Accounts. In: vom Brocke J, Mendling J (eds) Business process management cases: digital innovation and business transformation in practice, vol 1. Springer, Cham, pp 593-610

Armistead C, Pritchard J-P, Machin S (1999) Strategic business process management for organisational effectiveness. Long Range Plan 32:96-106. https://doi.org/10.1016/S00246301(98)00130-7

Baird K, Jia HuK, Reeve R (2011) The relationships between organizational culture, total quality management practices and operational performance. Int J Oper Prod Manag t 31:789-814. https://doi.org/10.1108/01443571111144850

Bannister F (2001) Dismantling the silos: extracting new value from IT investments in public administration. Info Syst J 11:65-84. https://doi.org/10.1046/j.1365-2575.2001.00094.x

Benner MJ, Tushman ML (2003) Exploitation, exploration, and process management: the productivity dilemma revisited. Acad Manag Rev 28:238-256. https://doi.org/10.5465/AMR.2003. 9416096

Berardo R (2009) Processing complexity in networks: a study of informal collaboration and its effect on organizational success. Policy Stud J 37:521-539. https://doi.org/10.1111/j.1541-0072. 2009.00326.x

Berwick DM (1989) Continuous improvement as an ideal in health care. N Engl J Med 320:53-56. https://doi.org/10.1056/ NEJM198901053200110

Bezes P, Jeannot G (2018) Autonomy and managerial reforms in Europe: let or make public managers manage? Public Admin 96:3-22. https://doi.org/10.1111/padm.12361

Bhuiyan N, Baghel A (2005) An overview of continuous improvement: from the past to the present. Manag Decis 43:761-771. https://doi.org/10.1108/00251740510597761

Boyne GA (2002) Public and private management: what's the difference? J Manag Stud 39:97-122. https://doi.org/10.1111/ 1467-6486.00284

Caillier JG (2017) The impact of high-quality workplace relationships in public organizations. Public Admin 95:638-653. https://doi. org/10.1111/padm.12328

Calciolari S, Prenestini A, Lega F (2018) An organizational culture for all seasons? How cultural type dominance and strength influence different performance goals. Public Manag Rev 20:1400-1422. https://doi.org/10.1080/14719037.2017.1383784

Cameron KS, Quinn RE (2011) Diagnosing and changing organizational culture: based on the competing values framework, 3rd edn. Jossey-Bass, San Francisco

Corradini F, Polini A, Re B (2015) Inter-organizational business process verification in public administration. BPMJ 21:1040-1065. https://doi.org/10.1108/BPMJ-02-2014-0013

de Vries H, Bekkers V, Tummers L (2016) Innovation in the public sector: a systematic review and future research agenda. Public Admin 94:146-166. https://doi.org/10.1111/padm.12209

Demircioglu MA, Audretsch DB (2017) Conditions for innovation in public sector organizations. Res Policy 46:1681-1691. https:// doi.org/10.1016/j.respol.2017.08.004 
Denner M-S, Püschel LC, Röglinger M (2018) How to exploit the digitalization potential of business processes. Bus Inf Syst Eng 60:331-349. https://doi.org/10.1007/s12599-017-0509-x

Detert JR, Schroeder RG, Mauriel JJ (2000) A framework for linking culture and improvement initiatives in organizations. Acad Manag Rev 25:850-863. https://doi.org/10.5465/AMR.2000. 3707740

Diefenbach T, Sillince JA (2011) Formal and informal hierarchy in different types of organization. Organ Stud 32:1515-1537. https://doi.org/10.1177/0170840611421254

Distel B, Lindgren I (2019) Who are the users of digital public services? A critical reflection on differences in the treatment of citizens as 'users' in e-government research. In: Panagiotopoulos P, Edelmann N, Glassey O, Misuraca G, Parycek P, Lampoltshammer T, Re B (eds) Electronic participation: 11th ifip wg 8.5 international conference, vol 11686. Springer, pp 117-129

Dumas M, La Rosa M, Mendling J, Reijers HA (2018) Introduction to business process management. In: Dumas M, La Rosa M, Mendling J, Reijers HA (eds) Fundamentals of business process management, 2nd edn. Springer, Heidelberg, pp 1-33

Dunleavy P, Margetts H, Bastow S, Tinkler J (2006) New public management is dead: long live digital-era governance. J Public Admin Res Theor 16:467-494. https://doi.org/10.1093/jopart/ mui057

Field A (2009) Discovering statistics using IBM SPSS statistics, 3rd edn. Sage, Los Angeles

Fischer M, Imgrund F, Janiesch C, Winkelmann A (2020) Strategy archetypes for digital transformation: defining meta objectives using business process management. Inf Manag 57:103262. https://doi.org/10.1016/j.im.2019.103262

Flynn BB, Sakakibara S, Schroeder RG, Bates KA, Flynn EJ (1990) Empirical research methods in operations management. J Oper Manag 9:250-284. https://doi.org/10.1016/0272-6963(90)90098$\mathrm{X}$

Frey CB, Osborne MA (2017) The future of employment: how susceptible are jobs to computerisation? Technol Forecast Soc Change 114:254-280. https://doi.org/10.1016/j.techfore.2016.08. 019

Fryer KJ, Antony J, Douglas A (2007) Critical success factors of continuous improvement in the public sector. TQM Mag 19:497-517. https://doi.org/10.1108/09544780710817900

Gieske H, Duijn M, van Buuren A (2020a) Ambidextrous practices in public service organizations: innovation and optimization tensions in Dutch water authorities. Public Manag Rev 22:341-363. https://doi.org/10.1080/14719037.2019.1588354

Gieske H, George B, van Meerkerk I, van Buuren A (2020b) Innovating and optimizing in public organizations: does more become less? Public Manag Rev 22:475-497. https://doi.org/10. $1080 / 14719037.2019 .1588356$

Grau C, Moormann J (2014) Investigating the relationship between process management and organizational culture: literature review and research agenda. Manag Organ Stud. https://doi. org $/ 10.5430 /$ mos.v $1 \mathrm{n} 2 \mathrm{p} 1$

Hammer M (2015) What is business process management? In: vom Brocke J, Rosemann M (eds) Handbook on business process management 1: introduction, methods, and information systems, 2nd edn. Springer, Heidelbarg, pp 3-16

Heinrich CJ (2002) Outcomes-based performance management in the public sector: implications for government accountability and effectiveness. Public Admin Rev 62:712-725. https://doi.org/10. 1111/1540-6210.00253

Heinzl A, Leidner DE (2012) Information systems and culture. Bus Inf Syst Eng 4:109-110. https://doi.org/10.1007/s12599-0120211-y
Hickson DJ, Hinings CR, Lee CA, Schneck RE, Pennings JM (1971) A strategic contingencies' theory of intraorganizational power. Admin Sci Q 16:216. https://doi.org/10.2307/2391831

Ho AT-K (2002) Reinventing Local governments and the e-government initiative. Public Admin Rev 62:434-444. https://doi.org/ 10.1111/0033-3352.00197

Hofstede G, Neuijen B, Ohayv DD, Sanders G (1990) Measuring organizational cultures: a qualitative and quantitative study across twenty cases. Admin Sci Q 35:286-316. https://doi.org/ $10.2307 / 2393392$

Houy C, Fettke P, Loos P (2010) Empirical research in business process management - analysis of an emerging field of research. BPMJ 16:619-661. https://doi.org/10.1108/14637151011065946

Hribar B, Mendling J (2014) The correlation of organizational culture and success of BPM adoption. In: Assoc Inf Syst (ed) ECIS 2014 Proceedings, pp 1-16

Hurley RF, Hult GTM (1998) Innovation, market orientation, and organizational learning: an integration and empirical examination. J Mark 62:42-54. https://doi.org/10.1177/ 002224299806200303

Indihar Štemberger M, Buh B, Milanovic Glavan L, Mendling J (2018) Propositions on the interaction of organizational culture with other factors in the context of BPM adoption. BPMJ 24:425-445. https://doi.org/10.1108/BPMJ-02-2017-0023

Indihar-Štemberger M, Jaklič J (2007) Towards E-government by business process change? A methodology for public sector. Int $\mathbf{J}$ Inf Manag 27:221-232. https://doi.org/10.1016/j.ijinfomgt.2007. 02.006

Jayaram J, Ahire SL, Dreyfus P (2010) Contingency relationships of firm size, TQM duration, unionization, and industry context on TQM implementation - a focus on total effects. J Oper Manag 28:345-356. https://doi.org/10.1016/j.jom.2009.11.009

Johns G (2017) Reflections on the 2016 decade award: incorporating context in organizational research. Acad Manag Rev 42:577-595. https://doi.org/10.5465/amr.2017.0044

Jos PH, Tompkins ME (2009) Keeping it public: defending public service values in a customer service age. Public Admin Rev 69:1077-1086. https://doi.org/10.1111/j.1540-6210.2009.02065. $\mathrm{X}$

King WR, He J (2005) External validity in IS survey research. CAIS 16:880-894. https://doi.org/10.17705/1CAIS.01645

Klischewski R (2004) Information integration or process integration? How to achieve interoperability in administration. In: Traunmüller R (ed) Proceedings 3rd international conference on Electronic government, Zaragoza, vol 3183. Springer, New York, pp 57-65

Knott AM, Vieregger C (2020) Reconciling the firm size and innovation puzzle. Organ Sci 31:477-488. https://doi.org/10. $1287 /$ orsc. 2019.1310

Kregel I (2018) Assessing the readiness of public administration's organisational culture for business process management: results from a pilot study in Germany. In: 25th annual EurOMA conference proceedings

Kregel I, Coners A (2018) Introducing Lean Six Sigma to a German municipality: an action research report. IJLSS 9:221-237. https://doi.org/10.1108/IJLSS-02-2017-0019

Lee AS, Baskerville RL (2003) Generalizing generalizability in information systems research. Inf Syst Res 14:221-243. https:// doi.org/10.1287/isre.14.3.221.16560

Legner C, Eymann T, Hess T, Matt C, Böhmann T, Drews P, Mädche A, Urbach N, Ahlemann F (2017) Digitalization: opportunity and challenge for the business and information systems engineering community. Bus Inf Syst Eng 59:301-308. https://doi.org/10. 1007/s12599-017-0484-2

Leidner DE, Kayworth T (2006) A review of culture in information systems research: toward a theory of information technology 
culture conflict. MIS Q 30:357-399. https://doi.org/10.2307/ 25148735

Lewandowski M (2019) Public managers' perception of performance information: the evidence from Polish local governments. Public Manag Rev 21:988-1010. https://doi.org/10.1080/14719037. 2018.1538425

Lindgren I, Madsen CØ, Hofmann S, Melin U (2019) Close encounters of the digital kind: a research agenda for the digitalization of public services. Gov Inf Q 36:427-436. https://doi.org/10.1016/j.giq.2019.03.002

Lyons ST, Duxbury LE, Higgins CA (2006) A comparison of the values and commitment of private sector, public sector, and parapublic sector employees. Public Admin Rev 66:605-618. https://doi.org/10.1111/j.1540-6210.2006.00620.x

Marschollek O, Beck R (2012) Alignment of divergent organizational cultures in IT public-private partnerships. Bus Inf Syst Eng 4:153-162. https://doi.org/10.1007/s12599-012-0213-9

McCormack K, Johnson WC (2001) Business process orientation: gaining the e-business competitive advantage. Lucie Press, Boca Raton, St

McNulty T, Ferlie E (2004) Process transformation: limitations to radical organizational change within public service organizations. Organ Stud 25:1389-1412. https://doi.org/10.1177/ 0170840604046349

Meier KJ, Hicklin A (2008) Employee turnover and organizational performance: testing a hypothesis from classical public administration. J Public Admin Res Theor 18:573-590. https://doi.org/ 10.1093/jopart/mum028

Mendling J, Pentland BT, Recker J (2020) Building a complementary agenda for business process management and digital innovation. Eur J Inf Syst 29:208-219. https://doi.org/10.1080/0960085X. 2020.1755207

Mergel I, Edelmann N, Haug N (2019) Defining digital transformation: results from expert interviews. Gov Inf Q 36:101385. https://doi.org/10.1016/j.giq.2019.06.002

Mergel I, Ganapati S, Whitford AB (2020) Agile: a new way of governing. Public Admin Rev 81:161-165. https://doi.org/10. 1111/puar. 13202

Meyer JP, Allen NJ (1991) A three-component conceptualization of organizational commitment. Hum Resour Manag Rev 1:61-89. https://doi.org/10.1016/1053-4822(91)90011-Z

Moon MJ, Norris DF (2005) Does managerial orientation matter? The adoption of reinventing government and e-government at the municipal level. Info Syst J 15:43-60. https://doi.org/10.1111/j. 1365-2575.2005.00185.x

Mowday RT, Steers RM, Porter LW (1979) The measurement of organizational commitment. J Vocat Behav 14:224-247. https:// doi.org/10.1016/0001-8791(79)90072-1

Mulgan R (2000) "Accountability": an ever-expanding concept? Public Admin 78:555-573. https://doi.org/10.1111/1467-9299. 00218

Naranjo-Valencia JC，Jiménez-Jiménez D，Sanz-Valle R (2011) Innovation or imitation? The role of organizational culture. Manag Decis 49:55-72. https://doi.org/10.1108/ 00251741111094437

Niehaves B, Plattfaut R, Becker J (2013) Business process management capabilities in local governments: a multi-method study. Gov Inf Q 30:217-225. https://doi.org/10.1016/j.giq.2013.03.002

Ongena G, Ravesteyn P (2020) Business process management maturity and performance: a multi group analysis of sectors and organization sizes. BPMJ 26:132-149. https://doi.org/10. 1108/BPMJ-08-2018-0224

Peccei R, Giangreco A, Sebastiano A (2011) The role of organisational commitment in the analysis of resistance to change. Pers Rev 40:185-204. https://doi.org/10.1108/00483481111106075
Pinsonneault A, Kraemer K (1993) Survey research methodology in management information systems: an assessment. J Manag Inf Syst 10:75-105. https://doi.org/10.1080/07421222.1993. 11518001

Radnor Z, O'Mahoney J (2013) The role of management consultancy in implementing operations management in the public sector. Int J Oper Prod Manag 33:1555-1578. https://doi.org/10.1108/ IJOPM-07-2010-0202

Radnor Z, Osborne SP (2013) Lean: a failed theory for public services? Public Manag Rev 15:265-287. https://doi.org/10. 1080/14719037.2012.748820

Raharjo H, Eriksson H (2017) Exploring differences between private and public organizations in business excellence models. Int $\mathbf{J}$ Oper Prod Manag t 37:1795-1816. https://doi.org/10.1108/ IJOPM-09-2015-0593

Raisch S, Birkinshaw J, Probst G, Tushman ML (2009) Organizational ambidexterity: balancing exploitation and exploration for sustained performance. Organ Sci 20:685-695. https://doi.org/ 10.1287/orsc. 1090.0428

Roberts NC (2011) Beyond Smokestacks and silos: open-source, webenabled coordination in organizations and networks. Public Admin Rev 71:677-693. https://doi.org/10.1111/j.1540-6210. 2011.02406.x

Romzek BS (2000) Dynamics of public sector accountability in an era of reform. Int Rev Admin Sci 66:21-44. https://doi.org/10.1177/ 0020852300661004

Rosemann M, vom Brocke J (2015) The six core elements of business process management. In: vom Brocke J, Rosemann M (eds) Handbook on business process management 1: introduction, methods, and information systems, 2nd edn. Springer, Heidelberg, pp 105-122

Salge TO, Vera A (2012) Benefiting from public sector innovation: the moderating role of customer and learning orientation. Public Admin Rev 72:550-559. https://doi.org/10.1111/j.1540-6210. 2012.02529.x

Schein EH (1996) Culture: the missing concept in organization studies. Admin Sci Q 41:229-240. https://doi.org/10.2307/ 2393715

Schmiedel T, vom Brocke J, Recker J (2013) Which cultural values matter to business process management? Results from a global Delphi study. BPMJ 19:292-317. https://doi.org/10.1108/ 14637151311308321

Schmiedel T, vom Brocke J, Recker J (2014) Development and validation of an instrument to measure organizational cultures' support of business process management. Inf Manag 51:43-56. https://doi.org/10.1016/j.im.2013.08.005

Schmiedel T, Recker J, vom Brocke J (2020) The relation between BPM culture, BPM methods, and process performance: evidence from quantitative field studies. Inf Manag 57:103175. https://doi. org/10.1016/j.im.2019.103175

Shafagatova A, Van Looy A (2021) A conceptual framework for process-oriented employee appraisals and rewards. Knowl Process Manag 28:90-104. https://doi.org/10.1002/kpm.1644

Škrinjar R, Bosilj-Vukšić V, Indihar-Štemberger M (2008) The impact of business process orientation on financial and nonfinancial performance. BPMJ 14:738-754. https://doi.org/10. $1108 / 14637150810903084$

Speklé RF, Widener SK (2018) Challenging issues in survey research: discussion and suggestions. J Manag Acc Res 30:3-21. https:// doi.org/10.2308/jmar-51860

Suzuki K, Hur H (2020) Bureaucratic structures and organizational commitment: findings from a comparative study of 20 European countries. Public Manag Rev 22:877-907. https://doi.org/10. 1080/14719037.2019.1619813

Syed R, Bandara W, French E, Stewart G (2018) Getting it right! Critical success factors of BPM in the public sector: a systematic 
literature review. Australas J Inf Syst 22:1-39. https://doi.org/10. 3127/ajis.v22i0.1265

Tabachnick BG, Fidell LS (2007) Using multivariate statistics, 5th edn. Always learning. Pearson, New York

Thomas JC (2013) Citizen, customer, partner: rethinking the place of the public in public management. Public Admin Rev 73:786-796. https://doi.org/10.1111/puar.12109

Van Looy A, de Backer M (2013) On the importance of organisational culture and structure in business process maturity. In: Assoc Inf Syst (ed) ICIS 2013 Proceedings, pp 1-16

Vanwersch RJB, Shahzad K, Vanderfeesten I, Vanhaecht K, Grefen P, Pintelon L, Mendling J, van Merode GG, Reijers HA (2016) A critical evaluation and framework of business process improvement methods. Bus Inf Syst Eng 58:43-53. https://doi.org/10. 1007/s12599-015-0417-x

vom Brocke J, Sinnl T (2011) Culture in business process management: a literature review. BPMJ 17:357-378. https://doi.org/10. $1108 / 14637151111122383$

vom Brocke J, Zelt S, Schmiedel T (2016) On the role of context in business process management. Int J Inf Manag 36:486-495. https://doi.org/10.1016/j.ijinfomgt.2015.10.002

vom Brocke J, Baier M-S, Schmiedel T, Stelzl K, Röglinger M, Wehking C (2021) Context-aware business process management. Bus Inf Syst Eng, in Print. https://doi.org/10.1007/s12599-02100685-0

Walker RM (2014) Internal and external antecedents of process innovation: a review and extension. Public Manag Rev 16:21-44. https://doi.org/10.1080/14719037.2013.771698

Weber K, Dacin MT (2011) The Cultural construction of organizational life: introduction to the special issue. Organ Sci 22:287-298. https://doi.org/10.1287/orsc. 1100.0632
Weerakkody V, Janssen M, Dwivedi YK (2011) Transformational change and business process reengineering (BPR): lessons from the British and Dutch public sector. Gov Inf Q 28:320-328. https://doi.org/10.1016/j.giq.2010.07.010

Wynen J, Verhoest K (2015) Do NPM-type reforms lead to a cultural revolution within public sector organizations? Public Manag Rev 17:356-379. https://doi.org/10.1080/14719037.2013.841459

Wynen J, van Dooren W, Mattijs J, Deschamps C (2019) Linking turnover to organizational performance: the role of process conformance. Public Manag Rev 21:669-685. https://doi.org/10. 1080/14719037.2018.1503704

Young MM (2020) Implementation of digital-era governance: the case of open data in U.S. cities. Public Admin Review 80:305-315. https://doi.org/10.1111/puar.13156

Zairi M (1997) Business process management: a boundaryless approach to modern competitiveness. BPMJ 3:64-80. https:// doi.org/10.1108/14637159710161585

Zelt S, Recker J, Schmiedel T, vom Brocke J (2018) Development and validation of an instrument to measure and manage organizational process variety. PLoS ONE 13:e0206198. https://doi.org/10.1371/journal.pone.0206198

Zhang F, Feeney MK (2020) Engaging through technology: the role of administrative culture and mandates. Public Manag Rev 22:1423-1442. https://doi.org/10.1080/14719037.2019.1630475

Zu X, Robbins TL, Fredendall LD (2010) Mapping the critical links between organizational culture and TQM/Six Sigma practices. Int J Prod Econ 123:86-106. https://doi.org/10.1016/j.ijpe.2009. 07.009 